\title{
Pollen morphology of subfamily Malvoideae (Malvaceae sensu lato) in Thailand
}

\author{
SURAPON SAENSOUK ${ }^{1}$, PIYAPORN SAENSOUK ${ }^{2, \vartheta}$ \\ ${ }^{1}$ Plant and Invertebrate Taxonomy and Its Applications Unit Group, Biodiversity Program, Walai Rukhavej Botanical Research Institute, Mahasarakham \\ University, Kantarawichai, Maha Sarakham, 44150, Thailand \\ ${ }^{2}$ Plant and Invertebrate Taxonomy and Its Applications Unit Group, Department of Biology, Faculty of Science, Mahasarakham Univ ersity, \\ Kantharawichai, Maha Sarakham, 44150, Thailand. `email: pcornukaempferia@yahoo.com
}

Manuscript received: 17 October 2021. Revision accepted: 28 November 2021.

\begin{abstract}
Saensouk S, Saensouk P. 2021. Pollen morphology of subfamily Malvoideae (Malvaceae sensu lato) in Thailand. Biodiversitas 22: 5633-5643. The pollen morphology of 19 species with eight variants and ten genera of subfamily Malvoideae (Malvaceae sensu lato) were investigated by light and scanning electron microscopy. The pollen was monad, spheroidal shaped and 45.64-168.00 $\mu \mathrm{m}$ in size. The pollen grains of all species were pantoporate. All pollen had radial symmetry and were apolar. The spines pollen grain of the subfamily Malvoideae in Thailand can be divided into six types. The arrangement of spines on pollens in this study can be divided into two groups. The pollen had various exine sculptures (granulate, microreticulate, and subpsilate). Spines were found to be echinate, baculate, and spinule. Pollen size, aperture, exine sculpture and spine index can be used as characters to identify the subfamily Malvoideae species. Therefore, a key to the 19 species with eight variants and ten genera of subfamily Malvoideae in this study based on pollen morphology was provided. Eight species were studied for their pollen morphology for the first time.
\end{abstract}

Keywords: Malvaceae, Malvoideae, pollen morphology, Thailand

\section{INTRODUCTION}

The family Malvaceae sensu lato is a large family of herbs, shrubs and trees, comprising about 244 genera with c. 4225 species (Kew Science 2021). This large family is composed of nine subfamilies: Byttnerioideae (26 genera, 650 species), Grewioideae (25 genera, 770 species), Sterculioideae (formerly Sterculiaceae, in part; 12 genera, 430 species), Tilioideae (formerly Tiliaceae, in part; three genera, 50 species), Dombeyoideae (c. 20 genera, $c .380$ species), Brownlowioideae (c. eight genera, $c .70$ species), Helicteroideae: (8-12 genera, 10-90 species), Malvoideae (formerly Malvaceae; 78 genera, 1,670 species) and Bombacoideae (formerly Bombacaceae, in part; 12 genera, 120 species) that encompass the majority of the morphological and taxonomic diversity in the subfamily (Bayer et al. 1999; Bayer and Kubitzki 2003; Kew Science 2021). The largest genera in terms of the number of species include Hibiscus (300 species), Sterculia (250 species), Dombeya (250 species), Pavonia (200 species) and Sida (200 species) (Kew Science 2021).

In the most recent treatment of Malvoideae, Bayer and Kutbitzki (2003) divided the subfamily into four tribes: Gossypieae, Hibisceae, Kydieae and Malveae. As considered here, tribe Malveae includes approximately 70 genera (c.900 species) that encompass the majority of the morphological and taxonomic diversity in the subfamily.

The pollen morphology of some Malvaceae species have been studied by several researchers, namely Surova and Velieve (1984), Christensen (1986), Culhane and Blackmore (1988), El Naggar (2004), El Naggar and Sawady (2008), and Saensouk and Saensouk (2020).
Many characteristics of pollen grains, i.e., size, aperture, spine index and exine sculpture can be used to identify of the plant species. In Thailand, the pollen morphology of this family has only limited work by Saensouk and Saensouk (2020) who studied the pollen morphology of the genus Helicteres in Thailand. Therefore, the aim of this study was to study the pollen morphology of the subfamily Malvoideae (Malvaceae sensu lato) in Thailand and use the pollen characters for the classification of the family.

\section{MATERIALS AND METHODS}

The pollen of 19 species with eight variants and ten genera from subfamily Malvoideae (Malvaceae sensu lato) from Thailand were studied between 2019 and 2021. The list of voucher specimens in the subfamily Malvoideae (Malvaceae sensu lato) is deposited in the Mahasarakham University Herbarium, Thailand (Table 1). Pollen grains were obtained from material fixed in $70 \%$ ethanol. Samples were analyzed using standard methods (acetolysis) described by Erdtman (1966). The pollen was studied by light microscopy (LM) and scanning electron microscopy (SEM). For LM, the pollen grains were measured for 30 grains from each individual. For the observation by SEM, the pollen grains were dried, coated with a sputter coater and observed with a scanning electron microscope, JEOL: JSM 6460 LV. Palynological terminology follows that of Erdtman (1966) and Punt et al. (1994). The spine index was the proportions between the height and width of the spine at its base. 
Table 1. Specimens from 19 species with eight variants, ten genera were investigated and all specimens investigated are deposited at Mahasarakham University Herbarium, Thailand

\begin{tabular}{|c|c|c|}
\hline Species & Voucher & Location (Provinces) \\
\hline Abelmoschus esculentus (L.) Moench & P. Saensouk 01/56 & Maha Sarakham \\
\hline A. moschatus Medik. & P. Saensouk 02/56 & Maha Sarakham \\
\hline Abutilon $\times$ hybridum Voss & P. Saensouk 03/56 & Nakhon Phanom \\
\hline Ab. hirtum (Lam.) Sweet & P. Saensouk 04/56 & Sakon Nakhon \\
\hline Ab. indicum (L.) Sweet & P. Saensouk 05/56 & Khon Kaen \\
\hline Bombycidendron grewiifolium (Hassk.) Zoll. \& Moritzi & P. Saensouk $10 / 56$ & Chiang Mai \\
\hline Decaschistia siamensis Craib & P. Saensouk 06/56 & Petchabun \\
\hline Gossypium barbadense $\mathrm{L}$. & P. Saensouk 07/56 & Nong Khai \\
\hline Hibiscus sabdariffa L. & P. Saensouk 08/56 & Roi-Et \\
\hline H. glandulifer Craib & P. Saensouk 09/56 & Udorn Thani \\
\hline H. mutabilis $\mathrm{L}$. & P. Saensouk $11 / 56$ & Phetchaburi \\
\hline H. radiatus Cav. & P. Saensouk $12 / 56$ & Ubonratchathani \\
\hline H. rosa-sinensis L. (red flower) & P. Saensouk $13 / 56$ & Maha Sarakham \\
\hline H. rosa-sinensis L. (yellow flower) & P. Saensouk $14 / 56$ & Maha Sarakham \\
\hline H. rosa-sinensis L. (pink flower) & P. Saensouk $15 / 56$ & Maha Sarakham \\
\hline H. rosa-sinensis L. (orange flower) & P. Saensouk 16/56 & Maha Sarakham \\
\hline H. surattensis L. & P. Saensouk $17 / 56$ & Suratthani \\
\hline H. vitifolius $\mathrm{L}$. & P. Saensouk $18 / 56$ & Kalasin \\
\hline Malvaviscus arboreus Dill. ex Cav. (red flower) & P. Saensouk $19 / 56$ & Nonthaburi \\
\hline M. arboreus Dill. ex Cav. (white flower) & P. Saensouk $20 / 56$ & Nonthaburi \\
\hline Sida cordifolia L. (small leaf) & P. Saensouk $21 / 56$ & Kalasin \\
\hline S. cordifolia L. (large leaf) & P. Saensouk $22 / 56$ & Kalasin \\
\hline Thespesia populnea (L.) Sol. ex Corrêa & P. Saensouk 23/56 & Nakhon Ratchasima \\
\hline Urena lobata $\mathrm{L}$. & P. Saensouk 24/56 & Khon Kaen \\
\hline
\end{tabular}

\section{RESULTS AND DISCUSSIONS}

Tables 1 and 2 and Figures 1 and 2 show that the pollen grains in 19 species with eight variants and ten genera of the subfamily Malvoideae (family Malvaceae sensu lato) were collected from several places in Thailand. All species and specimens were reported to be generally spheroidally shaped, with radials symmetrical. The present study is in accordance with Perveen et al. (1994) and EI Naggar (2004) that the pollen grains in Malvaceae are usually spheroidal and prolate or colporate with an echinate sculpture. At the same time, only spheroidal with echinate sculpture pollen grains were recognized by Chistensen (1986) and Bibi et al. (2008, 2010). The sizes of the pollen grains ranged between 45.64-214.50 $\mu \mathrm{m}$. The pollen sizes of this study were found to be very large, large, gigantic and medium. The smallest pollen grains were found in Abutilon indicum $(45.64 \mu \mathrm{m})$ whiles the largest pollen grains were found in Thespesia populnea $(214.50 \mu \mathrm{m})$. The aperture of this study found to be pantoporate. All pollen grains had radial symmetry and were apolar. Granulate, microreticulate, and subpsilate were exine sculpturing. The pollen grains in this study were found to have various spines in the exine sculptures (echinate, baculate, and spinule). The lengths of the spines ranged from 3.33 (Abutilon $\times$ hybridum) to 23.74 (Decaschistia siamensis) $\mu \mathrm{m}$. The spine indexes ranged from 0.76 (Abutilon $\times$ hybridum) to 3.08 (Abelmoschus esculentus) $\mu \mathrm{m}$. The pollen size, aperture, exine sculpture and spine index can be used as characters to identify of the subfamily of Malvoideae species.

\section{General description of subfamily Malvoideae pollen morphologies in Thailand}

Description: Pollen grains aperture pantoporate, apolar, radial symmetry, spheroidal. Exine sculpturing granulate, microreticulate, and subpsilate. Spines echinate, baculate, and spinule. The spine shape apex sharp-pointed or blunt, length 23.74-3.33 $\mu \mathrm{m}$, width 10.53-3.22 $\mu \mathrm{m}$. Spines and apertures are arraged horizontal regulation, random - the spine index 3.08-0.76 (Table 2, Figures 1 and 2).

\section{The aperture of pollen in the subfamily Malvoideae from Thailand}

The aperture of pollen in subfamily Malvoideae from Thailand in this study was presented pantoporate (Figures 1 and 2). Therefore, this character cannot be used for identification in this study.

\section{Exine sculpturing of pollen grain in subfamily Malvoideae in Thailand}

Various exine sculpturing forms on pollens of all species from the subfamily Malvoideae in this study were reported. Therefore, it can be separated into two exine sculptures, i.e. granulate, microreticulate, and subpsilate. Five species - Abutilon $\times$ hybridum, $H$. glanduliferus, $H$. mutabilis, Sida cordifolia (large leaf), and Urena lobata had been found microreticulate on exine sculpture. Whereas the exine sculpture pollens of remaining taxa were found to be subpsilate (Table 2). However, Bibi et al. (2010) reported exine sculpture or tectum sculpture between the spines of family Malvaceae, which was microrecticulate-punctuate, granulate, punctuate, sub psilate, smooth, sub echinate and verrucate. 

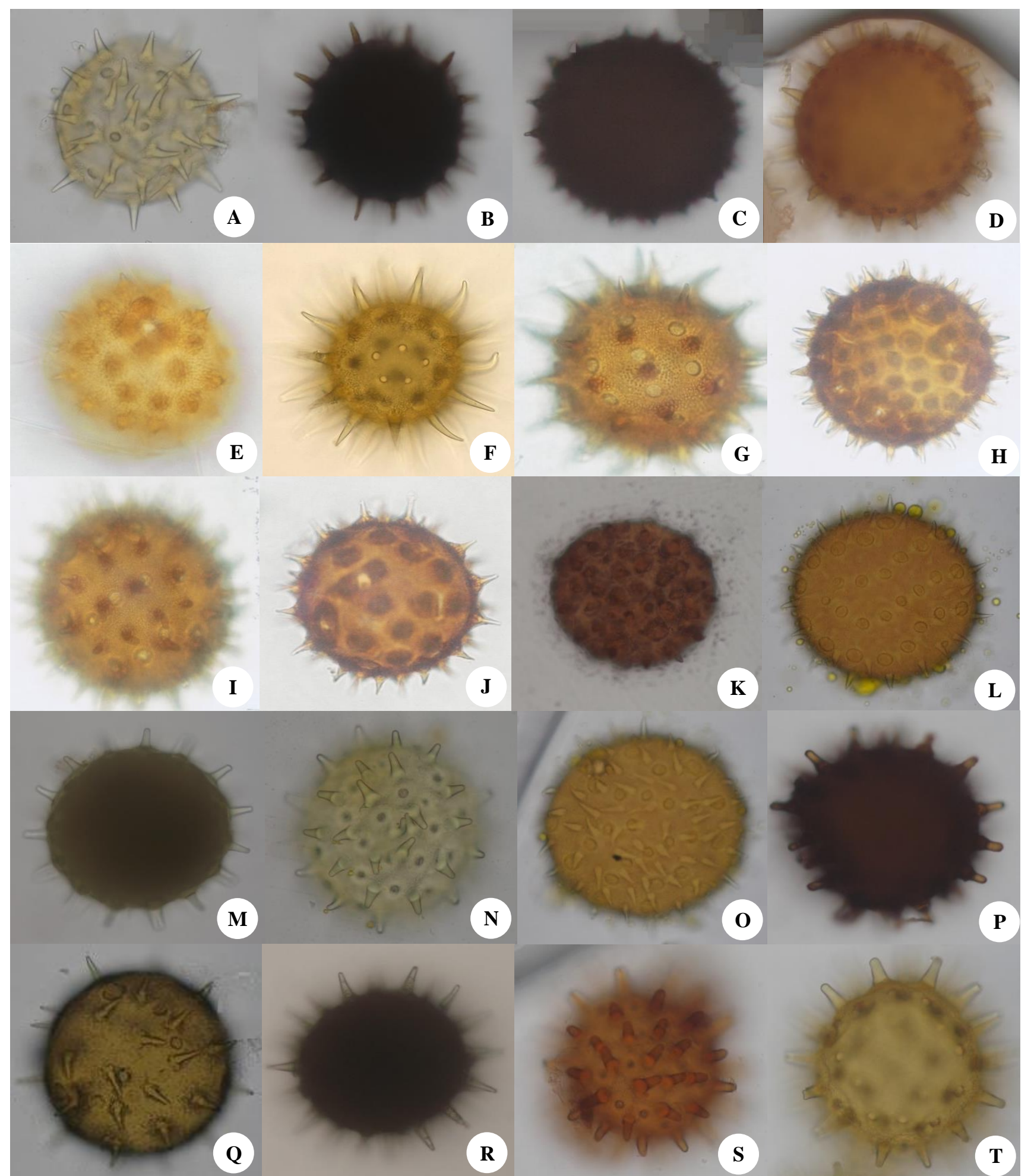

N
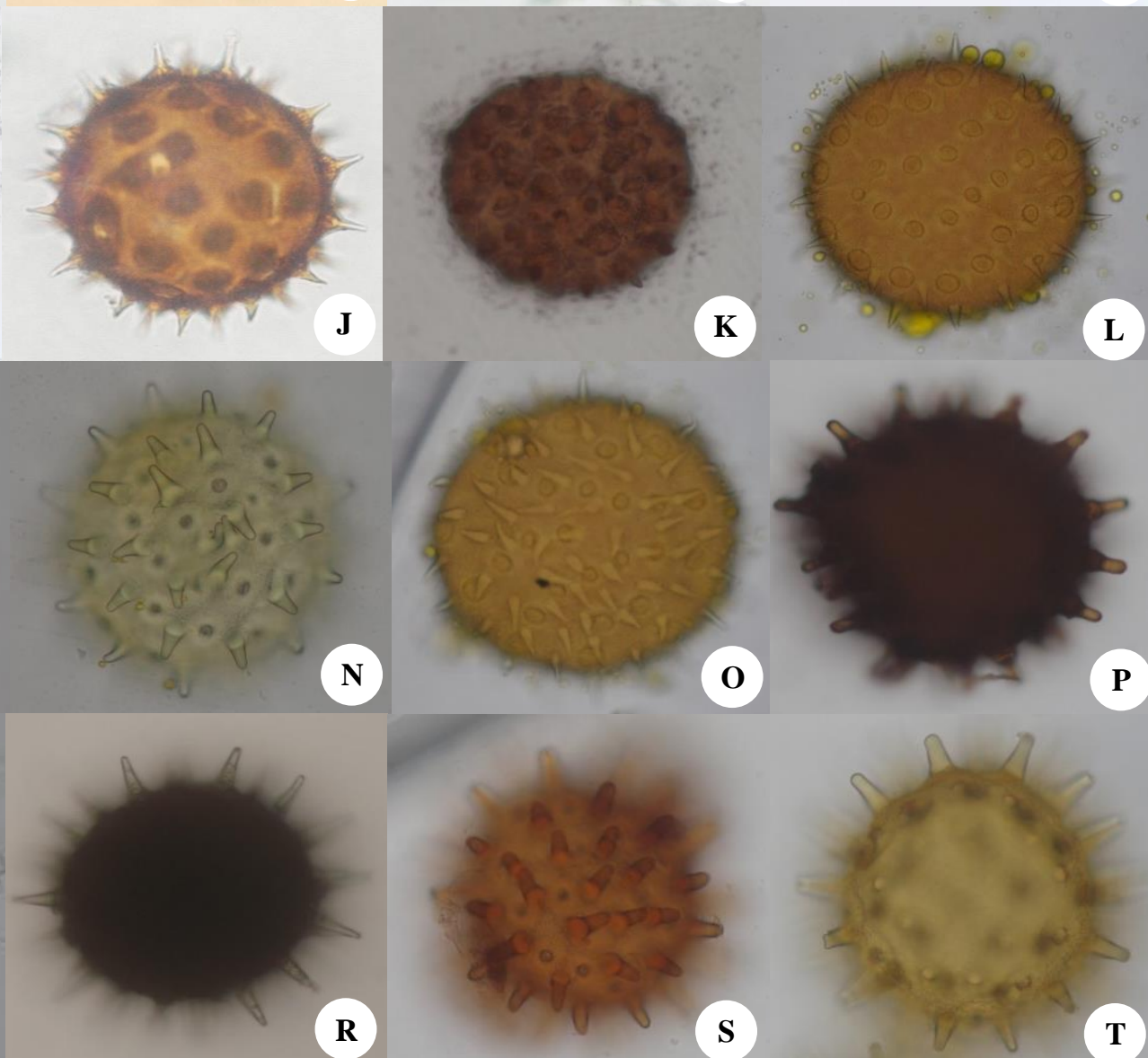

O
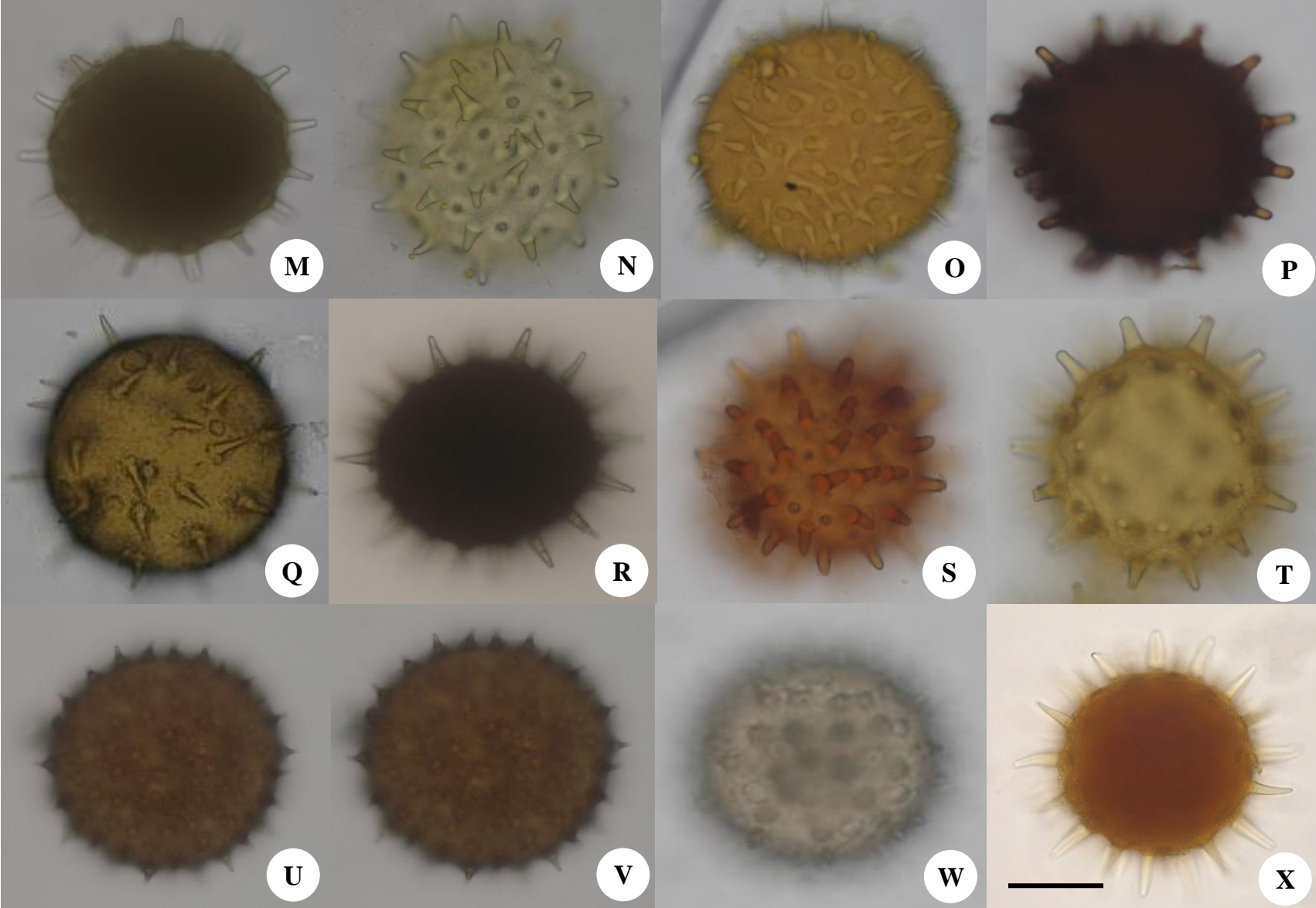

S

T

V

W

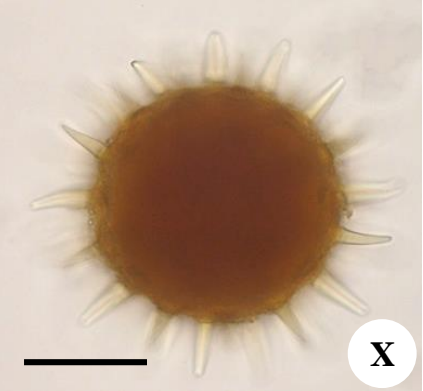


Figure 1. Light micrographs of pollen grains of: A. Abelmoschus esculentus, B. A. moschatus, C. Abutilon $\times$ hybridum, D. Ab. hirtum, E. Ab. idicum, F. Bombycidendron grewiifolium, G. Decaschistia siamensis, H. Gossypium barbadense, I. Hibiscus sabdariffa, J. H. glanduliferus, K. H. mutabilis, L. H. radiates, M. H. rosa-sinensis (red flower), N. H. rosa-sinensis (yellow flower), O. H. rosa-sinensis (pink flower), P. H. rosa-sinensis (orange flower), Q. H. surattensis, R. H. vitifolius, S. Malvaviscus arboreus (red flower), T. M. arboreus (white flower), U. Sida cordifolia (small leaf), V. S. cordifolia (large leaf), W. Thespesia populnea, X. Urena lobata )Scale bars $=40 \mu \mathrm{m}($

\section{The spine of pollen from the subfamily Malvoideae in Thailand}

The spines of all taxa in this study were found echinate, baculate, and spinule. The spinule was found in Abelmoschus esculentus, A. moschatus, Abutilon hirtum, Bombycidendron grewiifolium, Decaschistia siamensis, Hibiscus rosa-sinensis (pink flower), and $H$. vitifolius. Echinate was recognized in Abutilon $\times$ hybridum, Ab. Indicum, Gossypium barbadense, Hibiscus glanduliferus, H. mutabilis, H. surattensis, Malvaviscus arboreus (white flower), Sida cordifolia (small leaf), S. cordifolia (large leaf), and Thespesia populnea. Baculate was presented in Hibiscus sabdariffa, $H$. radiates, $H$. rosa-sinensis (red flower), $H$. rosa-sinensis (yellow flower), $H$. rosa-sinensis (orange flower), Malvaviscus arboreus (red flower), and Urena lobata. The spines were evenly distributed over the entire surface of the pollen grains and varied in length, shape, density and apexes, which vary as pointed, rounded blunt and bulbous. Erdtman (1966) and Bibi et al. (2010) reported the spine of Malvaceae pollen in some species, which agrees with this study (Table 2).

\section{Spine shape of pollen from the subfamily Malvoideae in Thailand}

The shapes of the spines were variable in length with sharp-pointed or blunt apices. The longest spines were recorded in Decaschistia siamensis $(23.74 \mu \mathrm{m})$ and the smallest in Abutilon $\times$ hybridum $(3.33 \mu \mathrm{m})$. The widths of the spines were found to be between $10.53 \mu \mathrm{m}$ (Decaschistia siamensis) and $3.22 \mu \mathrm{m}$ (Thespesia populnea) (Table 2). The spine was conical with straight sides in most of the plants in this study (Table 2). Curved spines were sometimes found in both variants of Sida cordifolia. In Abutilon $\times$ hybridum, Ab. indicum, Gossypium barbadense, H. glanduliferus, H. mutabilis L., H. surattensis L., Sida cordifolia (small leaf), S. cordifolia (large leaf) and Thespesia populnea (L.) Sol. ex Correa, the spines were raised on rounded bases, which were formed by an increase in the length of the columellae. The results of this study showed that the spines were divided into seven spine types, namely spine types 1 to 6 . While Bibi et al. (2010) reported two spine types, namely monomorphic and dimorphic spine types.

\section{Spine index of pollen from the subfamily Malvoideae in Thailand}

The spine index in this study was found to be between Abelmoschus esculentus (3.08) and Abutilon $\times$ hybridum (0.76) (Table 2). Shaheen et al. (2009b) used a spine index for the first time to characterize the pollen of the genus
Malva, and found that it was of significant taxonomic importance.

The spine types of pollen in subfamily Malvoideae from Thailand:

This study was found various spines of pollens in the subfamily Malvoideae from Thailand. Therefore, the spines pollen grain of subfamily Malvoideae in Thailand can be divided into six types (Table 2, Figures 1-2).

Spine type 1: The characteristic was not broad at the base. The width of the spiny base is similar to the apex spiny, gradually tapering towards an apex with a blunt tip. Six species were recorded in the type, namely Abelmoschus esculentus (Figures 1A, 2A1-A2), Hibiscus radiates (Figures 1L, 2L1-L2), H. rosa-sinensis (red flower) (Figures 1M, 2M1-M2), H. rosa-sinensis (orange flower) (Figures 1P, 2P1-P2), Malvaviscus arboreus (red flower) (Figures 1S, 2S1-S2) and Urena lobata (Figures 1X, 2X1$\mathrm{X} 2$ ).

Spine type 2: The characteristic was broad at the base, gradually tapering towards the apex with a more or less acute tip, i.e. Abutilon $\times$ hybridum (Figures 1C, 2C1-C2), Ab. indicum (Figures 1E, 3E1-E2), Gossypium brazilliense (Figures 1H, 2H1-H2), Hibiscus mutabilis (Figures $1 \mathrm{~K}$, 2K1-K2), $H$. surattensis (Figures 1Q, 2Q1-Q2), Sida cordifolia (small leaf) (Figures 1U, 2U1-U2), S. cordifolia (large leaf) (Figures 1V, 2V1-V2) and Thespesia populnea (Figures 1W, 2W1-W2) were recognized in this spine type.

Spine type 3: The characteristic was not broad at the base. The width of the spiny base is similar to the apex spiny, gradually tapering towards an apex with a more or less acute tip. Five species (Abelmoschus moschatus (Figures 1B, B1-B2), Abutilon hirtum (Figures 1D, 2D1D2), Bombycidendron grewiifolium (Figures 1F, 2F1-F2), Decaschistia siamensis (Figures 1G, 2G1-G2), H. rosasinensis (pink flower) (Figures 1O, 2O1-O2), and $H$. vitifolius (Figures 1R, 2R1-R2) were found in this spine type.

Spine type 4: The characteristic was concave at the base, gradually tapering towards the apex with a more acute tip, like drops of water. Only Hibiscus sabdariffa (Figures 1I, 2I1-I2) was recognized in this spine type.

Spine type 5: The characteristic was broad and spread flat at the base, gradually tapering towards the apex with a more acute tip. Only Hibiscus glanduliferus (Figures 1J, 2J1-J2) was recognized in this spine type.

Spine type 6: The characteristic was broad at the base, gradually tapering towards an apex with a blunt tip. Two species, Hibiscus rosa-sinensis (yellow flower) (Figures 1N, 2M1-M2) and Malvaviscus arboreus (white flower) (Figures 1T, 2T1-T2), were reported in this spine type. 


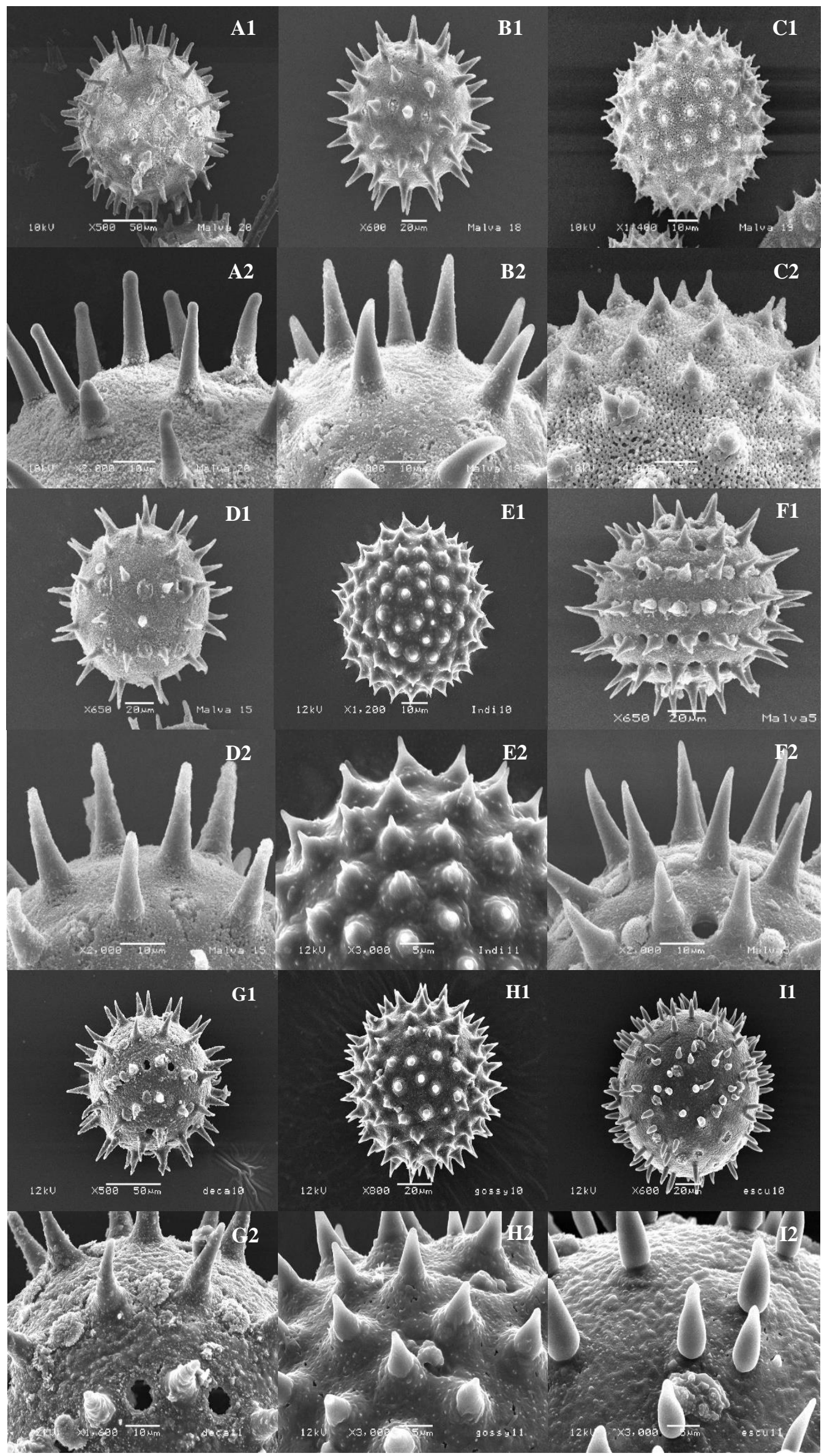




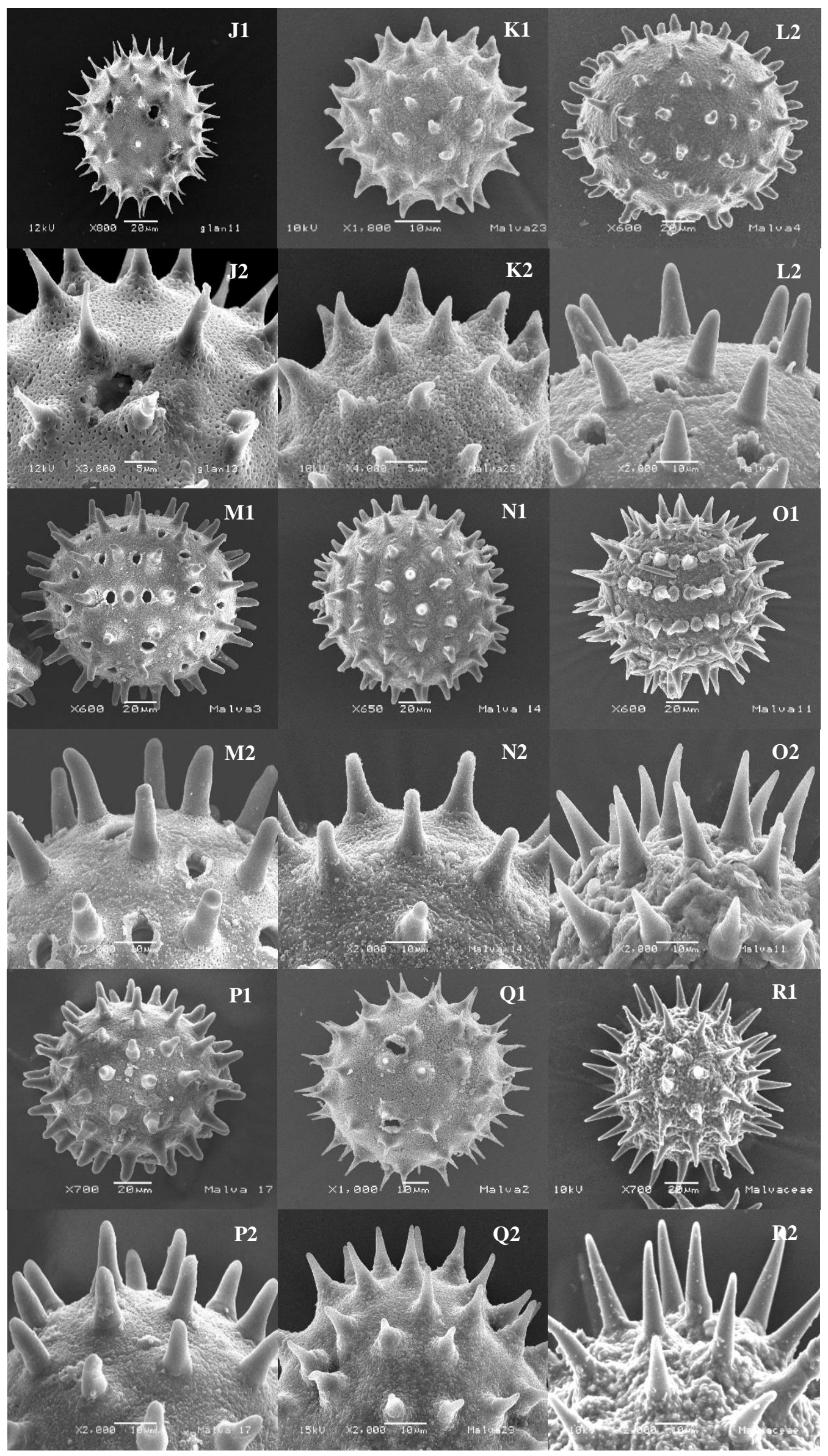




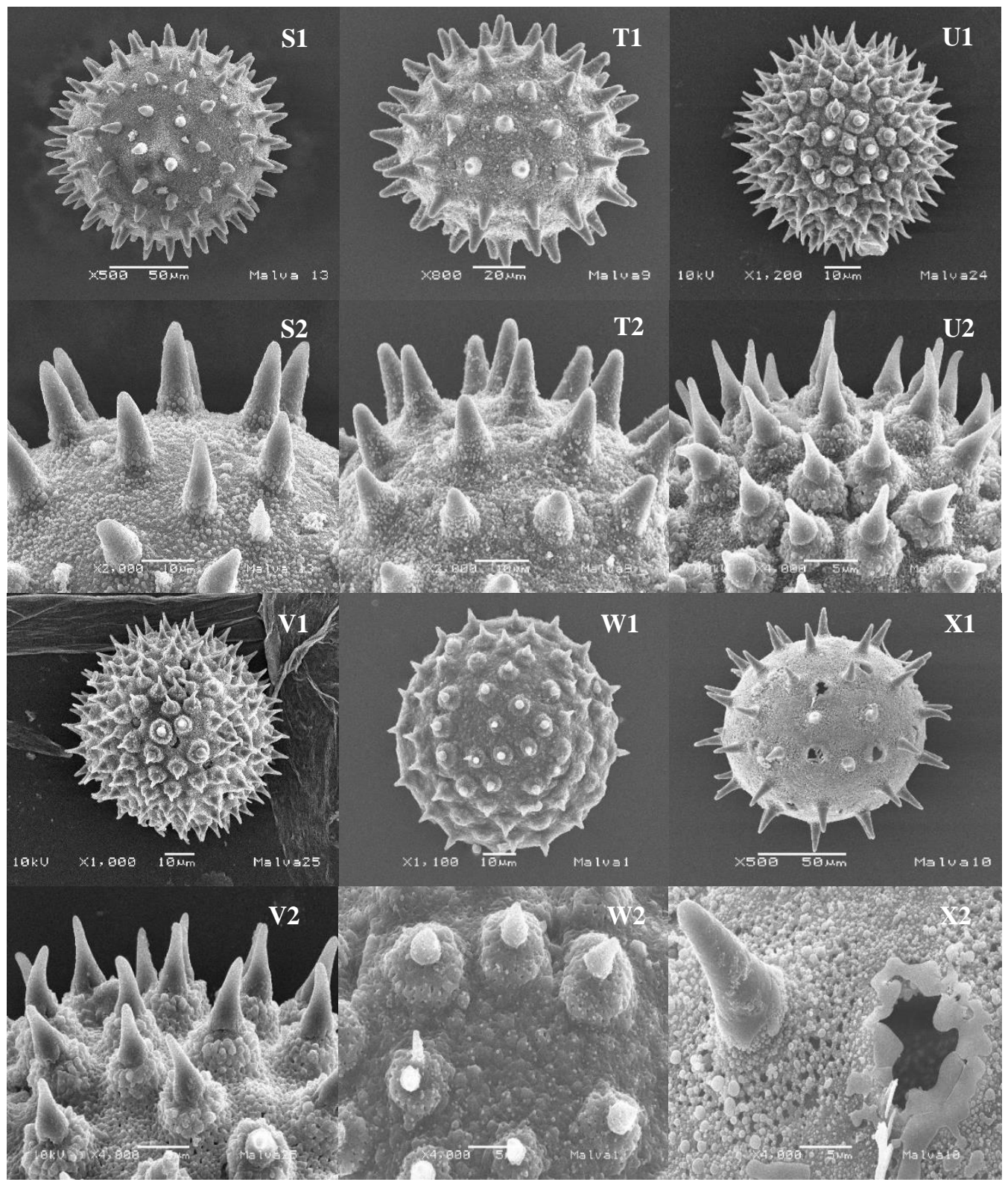

Figure 3. SEM micrographs of pollen grains of: A1-A2. Abelmoschus esculentus, B1-B2. A. moschatus, C1-C2. Abutilon $\times$ hybridum, D1-D2. Ab. hirtum, E1-E2. Ab. idicum, F1-F2. Bombycidendron grewiifolium, G1-G2. Decaschistia siamensis, H1-H2. Gossypium barbadense, I1-I2. Hibiscus sabdariffa, J1-J2. H. glanduliferus, K1-K2. H. mutabilis, L1-L2. H. Radiatus, M1-M2. H. rosa-sinensis (red flower), N1-N2. H. rosa-sinensis (yellow flower), O1-O2. H. rosa-sinensis (pink flower), P1-P2. H. rosa-sinensis (orange flower), Q1Q2. H. surattensis, R1-R2. H. vitifolius, S1-S2. Malvaviscus arboreus (red flower), T1-T2. M. arboreus (white flower), U1-U2. Sida cordifolia (small leaf), V1-V2. S. cordifolia (large leaf), W1-W2. Thespesia populnea, X1-X2. Urena lobata

\section{Arrangement of spines of pollen grain in subfamily Malvoideae in Thailand:}

The arrangement of spines on the pollen in this study could be divided into two groups, i.e., Group A and Group B (Table 2).

Group A: Spines and apertures were arraged horizontal regulation. Bombycidendron grewiifolium and Hibiscus rosa-sinensis (pink flower) were recognized in this group.

Group B: Spines and apertures were arranged randomly. All species and all samples except Bombycidendron grewiifolium and Hibiscus rosa-sinensis (pink flower) were recognized in this group.

\section{Pollen shape}

The shape of the pollen grains was spheroidal in all taxa. These results agree with those of Christensen (1986), Perveen et al. (1994), El Naggar (2004), Babi et al. (2008) and Shaheen et al. (2009a, b). Shaheen et al. (2009b) studied the pollen shape of Abutilon, which was sub-oblate to oblate-spheroidal (Table 2).

\section{Pollen size}

The pollen sizes of this study was found medium (1 species), large (8 species), very large (10 species with 6 variants) and gigantic (1 species) (Table 2). All pollens in 
this study were ranged from 45.64 (Abutilon indicum)214.50 (Thespesia populnea) $\mu \mathrm{m}$, which differed from the report of Tahavi (2000) that Hibiscus pollen was the largest among all the genera of the family. Bibi et al. (2008) reported that the pollen grains of Malvaviscus arboreus had the largest pollen size.

Genus Abelmoschus: The pollen size in this study was 61.73-109.25 $\mu \mathrm{m}$ (A. esculentus and A. moschatus) (Table 2). Christensen (1986) found the pollen size of Abelmoschus crinitus was $122 \times 127 \mu \mathrm{m}$, which was larger than in this study. On the other hand, Bibi et al. (2010) reported the pollen size of $A$. esculentus as $160 \times 140 \mu \mathrm{m}$.

Genus Abutilon: The pollen size of the three species in this genus (Table 2) was 45.64-127.10 $\mu \mathrm{m}$. Christensen (1986) recognized a pollen size of five species, including A. hirtum $(47 \times 43-75 \times 66 \mu \mathrm{m})$, which was smaller than this study $(A$. hirtum $=127.10 \mu \mathrm{m})$. Moreover, Bibi et al. (2010) investigated the pollen size of $A b$. indicum $(69 \mu \mathrm{m})$, which was smaller than in this study (Table 2). Shaheen et al. (2009b) reported the smallest pollen size from the polar axis of Abutilon molle $(37.5 \mu \mathrm{m})$; similar to that of $\mathrm{El}$ Naggar (2004) who reported the smallest pollen size of $A$. theophrasti $(37 \mu \mathrm{m})$, but in this study, the smallest pollen size was $45.64 \mu \mathrm{m}$ in $A b$. indicum. Therefore, the smallest pollen size in the family Malvaceae was the pollen in the genus Abutilon.

Genus Bombycidendron: The very large pollen size was $126.20 \mu \mathrm{m}$, which was found only in Bombycidendron grewiifolium. This is the first report of this.

Genus Decaschistia: The very large pollen size was found in this study (Decaschistia siamensis $=112.60 \mu \mathrm{m}$ ). This study was similar to the report of Christensen (1986).

Genus Gossypium: There was only one species in this study of pollen size $(G$. barbadense $=78.60 \mu \mathrm{m})$. Christensen (1986) studied the pollen size of G. hirsutum $(79 \times 77 \mu \mathrm{m})$.

The genus Hibiscus: The pollen morphology of the genus Hibiscus was apolar according to in the previous study by Perveen et al. (1994) and El Naggar (2004). The pollen size of seven species with four variants (Table 2) was large (74.17-83.42 $\mu \mathrm{m})$ to very large (109.18-151.42 $\mu \mathrm{m})$. The large pollen sizes have been found in three species, i.e. Hibiscus glanduliferus, $H$. mutabilis, and $H$. surattensis. In the other hand, the very large pollen sizes have been found in four species with four variants, i.e. Hibiscus sabdariffa, $H$. radiates, $H$. rosa-sinensis (red flower), $H$. rosa-sinensis (yellow flower), $H$. rosa-sinensis (pink flower), $H$. rosa-sinensis (orange flower), and $H$. vitifolius. While, El Naggar (2004) investigated the pollen size of $H$. rosa-sinensis is $73-75 \mu \mathrm{m}$, but it differs from this study, ranging from 109-151.42 $\mu \mathrm{m}$, due to the effect of different regions and environments such as air, soil, humid or moist. Perveen et al. (1994) also reported the pollen size of the genus Hibiscus which is 87.3-116.6 $\mu \mathrm{m}$. Christensen
(1986) studied pollen of Malvaceae and found that pollen size of Hibiscus (14 species examined including $H$. sabdariffa and $H$. surattensis) is $83-115 \mu \mathrm{m}$ differs from this study (74.17-151.42 $\mu \mathrm{m})$ due to the effect of different regions and environments such as air, soil, humid or moist. Babi et al. (2010) described pollen size of the genus Hibiscus ranging from $124-169 \mu \mathrm{m}$ but the pollen size of H. rosa-sinensis is $124-165 \mu \mathrm{m}$. Shaheen et al. (2009a, b) studied pollen of the genus Hibiscus ranging from 80-170 $\mu \mathrm{m}$. The present studies are also agree with the previous authors and reported the pollen size of the genus Hibiscus in the range of 74.17-151.42 $\mu \mathrm{m}$. At the same time, in $H$. rosa-sinensis range from 109-151.42 $\mu \mathrm{m}$. Therefore, the size of pollen $H$. rosa-sinensis is related to variation in species.

Genus Hibiscus: The pollen morphology of the genus Hibiscus was apolar according to previous studies by Perveen et al. (1994) and El Naggar (2004), while El Naggar (2004) investigated the pollen size of $H$. rosasinensis as 73-75 $\mu \mathrm{m}$, but it differs from this study. Perveen et al. (1994) also reported the pollen size of the genus Hibiscus, which was 87.3-116.6 $\mu \mathrm{m}$. Christensen (1986) studied the pollen of Malvaceae and found that the pollen size of Hibiscus (14 species examined including $H$. sabdariffa and $H$. surattensis) was 83-115 $\mu \mathrm{m}$, which differs from this study (74.17-151.42 $\mu \mathrm{m})$. Babi et al. (2008) described the pollen size of the genus Hibiscus ranged from $124-169 \mu \mathrm{m}$, but the pollen size of $H$. rosasinensis was 124-165 $\mu \mathrm{m}$. Shaheen et al. (2009a, b) studied the pollen of the genus Hibiscus, which ranged from 80$170 \mu \mathrm{m}$. The present study agrees with previous authors who reported the pollen size of the genus Hibiscus in the range of $74.17-151.42 \mu \mathrm{m}$. $H$. rosa-sinensis was in the range from 109-151.42 $\mu \mathrm{m}$. Therefore, the size of the pollen of $H$. rosa-sinensis was related to the variation in the species.

Genus Malvaviscus: The results from the Table 2 show the very large pollen sizes of Malvaviscus arboreus with two variants, i.e. red flower $(168 \mu \mathrm{m})$ and white flower $(149.75 \mu \mathrm{m})$ have been studied according to in the previous study by Babi et al. (2010).

Genus Sida: The large pollen sizes of both variants from Sida cordifolia, small leaf $(82.50 \mu \mathrm{m})$ and large leaf $(67.50 \mu \mathrm{m})$ have been studied, according to in the previous study by Chistensen (1986).

Genus Thespesia: The gigantic pollen size of Thespesia populnea ranged to $214.50 \mu \mathrm{m}$, according to the previous study by Chistensen (1986) but differs from Tahavi (2000) report that Hibiscus pollen was the largest among all the genera of the family. While, Bibi et al. (2008) reported the pollen grains of Malvaviscus arboreus to have the largest pollen size.

Genus Urena: Only Urena lobata was reported very large pollen size $(115.87 \mu \mathrm{m})$, according to the previous study by Chistensen (1986). 
Table 2. Pollen morphology data of 19 species with eight variants and 10 genera, subfamily Malvoideae (Malvaceae sensu lato) from Thailand

\begin{tabular}{|c|c|c|c|c|c|c|c|c|c|c|c|}
\hline Species & Pollen size $(\mu \mathrm{m})$ & & $\begin{array}{l}\text { Aperture } \\
\text { character }\end{array}$ & $\begin{array}{l}\text { Length of } \\
\text { spine }(\mu \mathrm{m})\end{array}$ & $\begin{array}{l}\text { Width of } \\
\text { spine }(\mu \mathrm{m})\end{array}$ & $\begin{array}{l}\text { Spine } \\
\text { index }\end{array}$ & Spine & $\begin{array}{l}\text { Arrangement } \\
\text { of spines }\end{array}$ & $\begin{array}{l}\text { Spine } \\
\text { type }\end{array}$ & $\begin{array}{l}\text { Exine } \\
\text { sculpture }\end{array}$ & Previous study \\
\hline Abelmoschus esculentus & $61.73 \pm 6.85$ & Large & Pantoporate & $23.42 \pm 2.10$ & $7.62 \pm 0.72$ & 3.08 & spinule & Group B & Type 1 & subpsilate & Bibi et al. (2010) \\
\hline A. moschatus & $109.25 \pm 5.05$ & Very large & Pantoporate & $22.5 \pm 1.02$ & $8.97 \pm 0.45$ & 2.51 & spinule & Group B & Type 3 & subpsilate & \\
\hline Abutilon $\times$ hybridum & $65.60 \pm 5.17$ & Large & Pantoporate & $3.33 \pm 1.20$ & $.37 \pm 0.51$ & 0.76 & echinate & Group B & Type 2 & microreticulate & \\
\hline Ab. hirtum & $127.10 \pm 4.52$ & Very large & Pantoporate & $21.57 \pm 1.22$ & $7.60 \pm 0.61$ & 2.84 & spinule & Group B & Type 3 & subpsilate & Chistensen (1986) \\
\hline Ab. indicum & $45.64 \pm 2.99$ & Medium & Pantoporate & $6.91 \pm 0.23$ & $7.59 \pm 0.34$ & 0.91 & echinate & Group B & Type 2 & subpsilate & Bibi et al. (2010) \\
\hline Bombycidendron grewiifolium & $126.20 \pm 4.77$ & Very large & Pantoporate & $23.42 \pm 1.91$ & $9.63 \pm 0.74$ & 2.43 & spinule & Group A & Type 3 & subpsilate & \\
\hline Decaschistia siamensis & $112.60 \pm 2.55$ & Very large & Pantoporate & $23.74 \pm 1.02$ & $10.53 \pm 0.82$ & 2.25 & spinule & Group B & Type 3 & subpsilate & Chistensen (1986) \\
\hline Gossypium barbadense & $78.60 \pm 3.62$ & Large & Pantoporate & $12.10 \pm 0.48$ & $7.51 \pm 0.34$ & 1.61 & echinate & Group B & Type 2 & subpsilate & \\
\hline Hibiscus sabdariffa & $119.30 \pm 3.24$ & Very large & Pantoporate & $12.01 \pm 0.53$ & $4.56 \pm 0.21$ & 2.63 & baculate & Group B & Type 4 & subpsilate & Chistensen (1986) \\
\hline H. glanduliferus & $76.30 \pm 3.24$ & Large & Pantoporate & $12.39 \pm 0.44$ & $6.54 \pm 0.23$ & 1.89 & echinate & Group B & Type 5 & microreticulate & \\
\hline H. mutabilis & $74.17 \pm 4.17$ & Large & Pantoporate & $7.25 \pm 1.37$ & $4.40 \pm 0.46$ & 1.65 & echinate & Group B & Type 2 & microreticulate & \\
\hline H. radiatus & $109.18 \pm 6.84$ & Very large & Panto & $12.22 \pm 2.73$ & $7.07 \pm 0.17$ & 1.73 & & Group B & Type 1 & subpsilate & \\
\hline H. rosa-sinen & 1 & arge & Pant & & 84 & 1. & baculate & & Type 1 & subpsilate & Bibi \\
\hline H. rosa-sinensis & $149.75 \pm 6.48$ & Very large & Pantoporate & 20 & $0 \pm 0.39$ & 1.73 & baculate & Group B & Type 6 & subpsilate & Bibi et al. (2010) \\
\hline H. rosa-sinensis (pink flower) & $110.42 \pm 6.86$ & Very large & Pantoporate & $15.29 \pm 1.37$ & $.70 \pm 0.53$ & 1.76 & le & Group A & Type 3 & subpsilate & Bibi et al. (2010) \\
\hline H. rosa-sinensis (orange flower) & $109.00 \pm 7.12$ & Very large & Pantoporate & $13.50 \pm 1.41$ & $8.73 \pm 0.45$ & 1.55 & baculate & Group B & Type 1 & subpsilate & Bibi et al. (2010) \\
\hline H. surattensis & $83.42 \pm 5.03$ & Large & Pantoporate & $10.03 \pm 0.75$ & $6.12 \pm 0.28$ & 1.64 & echinate & Group B & Type 2 & subpsilate & Chistensen (1986) \\
\hline H. vitifolius & $119.08 \pm 4.07$ & Very large & Pantoporate & $22.50 \pm 2.27$ & $9.10 \pm 0.31$ & 1.89 & spinule & Group B & Type 3 & subpsilate & \\
\hline Malvaviscus arboreus (red flower) & $168.00 \pm 6.93$ & Very large & Pantoporate & $14.43 \pm 3.24$ & $7.62 \pm 0.54$ & 1.89 & baculate & Group B & Type 1 & subpsilate & Bibi et al. (2010) \\
\hline M. arboreus (white flower) & $149.75 \pm 6.48$ & Very large & Pantoporate & $17.75 \pm 2.40$ & $9.43 \pm 0.72$ & 1.88 & & Group B & Type 6 & subpsilate & Bibi et al. (2010) \\
\hline Sida cordifolia (small leaf) & $82.50 \pm 6.09$ & Large & Pantoporate & $8.08 \pm 1.08$ & $5.10 \pm 0.20$ & 1.58 & echinate & Group B & Type 2 & microreticulate & Chistensen (1986) \\
\hline S. cordifolia (large leaf) & $67.50 \pm 5.84$ & Large & Pantoporate & $6.83 \pm 1.12$ & $.19 \pm 0.25$ & 1.10 & echin & Group B & Type 2 & granulate & Chistensen (1986) \\
\hline Thespesia populnea & & Gigantic & Pantoporate & $11.42 \pm 2.15$ & $3.22 \pm 0.36$ & 2.29 & & & Type 2 & subpsilate & Chistensen (1986) \\
\hline Urena lobata & $115.87 \pm 5.56$ & Very large & Pantoporate & 15.00 & $7.60 \pm 0.61$ & 1.97 & ba & p B & Type 1 & microreticulate & Chistensen (1986) \\
\hline
\end{tabular}




\section{Key to species based on pollen morphology}

It is constructed base on pollen morphology as below:

1. Arrangement of spines Group A …..................... 2 Arrangement of spines Group B .......................... 3

2. Spine index 2.43 ............ Bombycidendron grewiifolium Spine index 1.76 ........ Hibiscus rosa-sinensis (pink flower)

3. Exine sculpture granulate or microreticulate .............. 4 Exine sculpture subpsilate ............................. 8

4 Pollen very large size; spine baculate ….... Urena lobata Pollen large size; spine echinate ......................... 5

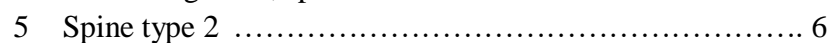
Spine type 5 .......................... Hibiscus glanduliferus

6 Spine index under $1.0 \ldots \ldots \ldots \ldots \ldots$......... Abutilon $\times$ hybridum

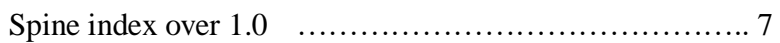

7 Exine sculpture granulate ....... Sida cordifolia (large leaf) Exine sculpture microreticulate ......... Hibiscus mutabilis

8 Spine spinule $\quad$.................................... 9

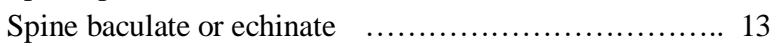

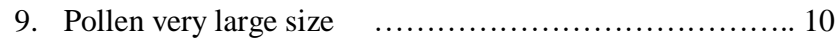
Pollen large size .................... Abelmoschus esculentus

10 Spine index under $2.0 \quad \ldots \ldots \ldots \ldots \ldots \ldots . . . . . . . . . . .1$ Hibiscus vitifolius

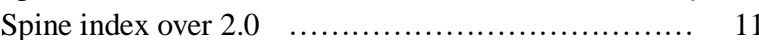

11 Pollen size under $115 \mu \mathrm{m}$.............................. 12 Pollen size over $115 \mu \mathrm{m}$.................... Abutilon hirtum

12 Spine index under 2.3; Pollen size over $110 \mu \mathrm{m}$

Decaschistia Spine index over 2.3; Pollen size under $110 \mu \mathrm{m}$

Abelmoschus moschatus

13 Spine echinate ..................................... 14 Spine baculate $\quad$.................................... 18

14 Pollen very medium size $\quad . . . . . . . . . \ldots \ldots . . . \quad$ Abutilon indicum Pollen large, very large or gigantic size ................ 15

15 Spine type 6 ......... Malvaviscus arboreus (white flower) Spine type 2 ..................................... 16

16 Pollen gigantic size .................. Thespesia populnea Pollen large or very large size $\ldots \ldots \ldots \ldots \ldots \ldots \ldots \ldots . \ldots 17$

17 Spine length $12.10 \mu \mathrm{m}$; spine width $7.51 \mu \mathrm{m}$; spine index 1.61 ................................... Gossypium barbadense Spine length $10.03 \mu \mathrm{m}$; spine width $6.12 \mu \mathrm{m}$; spine index 1.64 ................................ Hibiscus surattensis

18 Exine sculpture microreticulate ...Sida cordifolia (small leaf) Exine sculpture subpsilate $\quad$.......................... 19

19 Pollen size under $140 \mu \mathrm{m} \quad$............................ 20 Pollen size over $140 \mu \mathrm{m} \quad$......................... 22

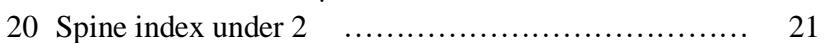
Spine index over $2 \quad$..................... Hibiscus sabdariffa

21 Spine length $12.22 \mu \mathrm{m}$; spine width $7.07 \mu \mathrm{m}$; spine index 1.73 ......................................... Hibiscus radiatus Spine length $13.50 \mu \mathrm{m}$; spine width $8.73 \mu \mathrm{m}$; spine index $1.55 \quad$................ Hibiscus rosa-sinensis (orange flower)

22 Spine type 1 .................................. 23 Spine type 6 ......... Hibiscus rosa-sinensis (yellow flower)

23 Pollen size $151.42 \mu \mathrm{m}$; spine length $15.72 \mu \mathrm{m}$; spine width $8.63 \mu \mathrm{m}$; spine index 1.83

Hibiscus rosa-sinensis (red flower) Pollen size $168 \mu \mathrm{m}$; spine length $14.43 \mu \mathrm{m}$; spine width 7.62 $\mu \mathrm{m}$; spine index 1.89 .... Malvaviscus arboreus (red flower)
In conclusion, the pollen morphology of 19 species with eight variants and ten genera of subfamily Malvoideae (Malvaceae sensu lato) from Thailand was studied under light and scanning electron microscopy. The pollen grains of all species were found to be monad, spheroidal in shape and 45.64-168.00 $\mu \mathrm{m}$ in size. The pollens in this study were recognized as pantoporate. All pollen grains had radial symmetry and were apolar. Exine sculpturing was granulate, microreticulate, and subpsilate. Spines were reported to be echinate, baculate, and spinule. Therefore, the spines of the pollen grains from the subfamily Malvoideae in Thailand can be divided into six types. The arrangement of spines on pollens in this study can be divided into two groups (Group A and Group B). Pollen size, aperture, exine sculpture and spine index can be used as characters to identify the subfamily Malvoideae species. The results showed that the pollens of four variants of $H$. rosa-sinensis were related in many pollen morphologies but differ in the pollen size, spine type, spine indexes and exine sculpture. For pollen morphology of both variants of Malvaviscus arboreus were closely related in many pollen morphologies of them but differs in the range of pollen size, spine type, spine indexes and exine sculpture. While, pollen morphology of both variants of Sida cordifolia were closely related in many pollen morphologies of them but differs in the range of pollen size, spine type, and spine indexes. Eight species, i.e. Abelmoschus moschatus, Abutilon $\times$ hybridum, Bombycidendron grewiifolium, Gossypium barbadense, Hibiscus glanduliferus, $H$. mutabilis, $H$. radiates, $H$. vitifolius, were studied for their pollen morphology for the first time. The key to all the species in this study was based on the morphology of the pollen provided.

\section{ACKNOWLEDGEMENTS}

This research project was financially supported by Mahasarakham University. We are especially grateful to the Department of Biology, Faculty of Science, Walai Rukhavej Botanical Research Institute and the Central Instrumentation Unit of the Faculty of Science, Mahasarakham University for their facilities. The authors are indebted to Dr. Jolyon Dodgson for language editing and suggestions to improve the manuscript. We would like to thank Ms. Rattikan Saensree and Ms. Thunchanok Moolthito for their excellent assistance with this experiment.

\section{REFERENCES}

Bayer C, Kubitzki K. 2003. Malvaceae. In: Kubitzki K (ed) The Families and Genera of Vascular Plants, Malvales, Capparales and NonBetalain Caryophyllales. Springer, Berlin. DOI: 10.1007/978-3-66207255-4_28.

Bayer C, Fay MF, De Bruun AY, Savolainen V, Morton CM, Kubitzki K, Chase MW. 1999. Support for an expanded family concept of Malvaceae within a recircumscribed order Malvales: A combined analysis of plastid atpB and rbcL DNA sequences. Bot J Linn Soc 129 (4): 267-303. DOI: 10.1111/j.1095-8339.1999.tb00505.x. 
Bibi N, Hussain M, Akhtar N. 2008. Palynological study of some cultivated species of genus Hibiscus from northwest frontier province (N.W.F.P.) Pakistan. Pak J Bot 40 (4): 1561-1569.

Bibi N, Akhtar N, Hussain M, Khan MJ. 2010. Systematic implications of the pollen morphology in the family Malvaceae from north west frontier province, Pakistan. Pak J Bot 42 (4): 2205-2214.

Christensen PB. 1986. Pollen morphological studies in the Malvaceae Grana 25: 95-117. DOI: 10.1080/00173138609428890.

Culhane KJ, Blackmore S. 1988. The Northwest European pollen flora, 41, Malvaceae. Rev Palaeobot Palynol 57 (1-2): 45-74. DOI: 10.1016/0034-6667(88)90046-2.

El Naggar SM, Sawady N. 2008. Pollen morphology of Malvaceae and its taxonomic significance in Yemen. Flora Mediterr 18: 431-439.

El Naggar SM. 2004. Pollen morphology of Egyptian Malvaceae: An assessment of taxonomic value. Turk J Bot 28: 227-240.

Erdtman G. 1966. Pollen Morphology and Plant Taxonomy: Angiosperms. Noble Offset Printers, New York, USA

Kew Science. 2021. World Checklist of Selected Plant Families (WCSP).
Perveen A, Siddiqui S, Fatima A, Qaiser M. 1994. Pollen flora of Pakistan-1. Malvaceae. Pak J Bot 26 (2): 421-440.

Punt W, Blackmore S, Le Thomas A, Nilsson S. 1994. Glossary of pollen and Spore Terminology. 73 pp. Utrecht: LPP Foundation.

Saensouk S, Saensouk P. 2020. Pollen morphology of Helicteres (Malvaceae s.1.) from Thailand. Agric Nat Resour 54 (4): 351-354.

Shaheen N, Khan MA, Hayat MQ, Yasmin G. 2009a. Pollen morphology of 14 species of Abutilon and Hibiscus of the family Malvaceae (sensu stricto). J Med Plants Res 3 (11): 921-929.

Shaheen N, Khan MA, Yasmin G, Hayat MQ, Ali S. 2009b. Taxonomic implication of palynological characters in the genus Malva L., family Malvaceae from Pakistan. Am-Eurasian J Agric Environ Sci 6 (6): 716-722.

Surova TD, Velieve HA. 1984. On the structure of the pollen wall in Malva sylvestris (Malvaceae). Bot Zhurn 69: 503-506.

Tahavi M. 2000. Palynological Studies of Arboreal Plants Growing in Lahore and their Impact on Aeropalynology. [Ph.D. Thesis]. Punjab University, Lahore. 